\title{
Respiratory disease in tea workers in Sri Lanka
}

\author{
C G URAGODA
}

From the Central Chest Clinic, Colombo, Sri Lanka

ABSTRACT Blending of different grades of tea is a very dusty process which exposes workers tid a fine fluff. One hundred and twenty-five tea blenders with an average service of 22.9 years in the industry were interviewed according to a standard questionnaire, and submitted to a clinicat and radiographical examination. The examination was repeated eight and 31 months later. total of 46 workers $(36 \%)$ had respiratory illness, 31 had chronic bronchitis $(24.8 \%)$, eight had asthma (6.4\%), and seven had active or inactive pulmonary tuberculosis $(5.6 \%)$. The prevalence of chronic bronchitis and asthma was more than that expected in the general population. It suggested that these two conditions are aetiologically related to long-term exposure to tea fluff.

The manufacture of tea is associated with discharge into the atmosphere of a fine dust known as tea fluff. It is a waste product which is largely removed by exhaust fans fitted to the factory. However, the tea that leaves the factory retains a considerable residue of this fluff which is subsequently liberated when different grades of tea are blended together before export. Workers engaged in both the manufacture and the blending of tea are exposed to this dust. The present study is the first investigation into the clinical and epidemiological aspects of lung disease resulting from long-term exposure to tea fluff.

Respiratory symptoms among tea workers were first recognised 60 years ago, but since then reports on the subject have been scanty. Castellani and Chalmers ${ }^{1}$ working in Sri Lanka described two allied conditions which they named tea factory cough and tea taster's disease. The former affected workers in tea factories, the symptoms being loss of weight, tiredness, and cough with mucopurulent expectoration. Tea tasters, whose duty was to judge the quality of tea, had a similar affection which was attributed to the inhalation of microorganisms on sniffing tea leaves. More recently, a case of asthma in a tea maker was reported. ${ }^{2}$ This man who supervised the manufacture of tea in a factory developed attacks of asthma whenever he entered the factory. Provocative inhalation of tea fluff reproduced the attack. Ebihara ${ }^{3}$ described two patients who were considered to have allergic symptoms of headache, cough, expectoration,

Address for reprint requests: Central Chest Clinic, Deans Road, Colombo 10, Sri Lanka. stridor, dyspnoea, and rhinitis which he thought were caused by airborne cilia from tea leaves.

At present Sri Lanka is the largest exporter of tea in the world. Its manufacture, which was do scribed in a previous report, ${ }^{2}$ is carried out numerous factories situated on estates throughout the tea-growing districts in the country. Exporte in Colombo buy different grades of tea in bulf from various estates at the weekly tea auctions Each tea has its own distinctive quality, and very often several grades of tea have to be blended 语 order to obtain a product which would satisfy the requirements of foreign buyers. Tea tasters, after taking into consideration the particle size, flavou and colour of the tea, provide the formula which lays down the proportion in which the teas selected by him should be mixed.

Blending of tea is done in Colombo by a fe large firms, one of which was selected for the present study. The tea, which is brought in ply wood boxes each containing 50 to $100 \mathrm{~kg}$, 顿 blended either manually or mechanically, pros vision for both processes being available side by side in a large common hall enclosed on all sides Ventilation is through open doors and windows.

Manual blending, which is not provided with any special mechanism for the extraction of fluff, is a unusually dusty process but it has the advantage of producing intimate mixing. In mechanical blents ing there is the possibility that the mixing blades may cut the tea particles into smaller sizes. The manual process is, therefore, preferred in cases where the buyers specify a large particle size.

In manual blending boxes of tea are emptied fol 
the blending floor to form separate heaps. Men and women workers, using spades, mix up these heaps and gather them into a single pile which is again divided into several lots. Finally, all the tea is brought together again into one large heap. These manoeuvres are designed to provide thorough mixing of the tea. Clouds of fluff are raised when spadefuls of tea are thrown to and fro during the process, and at the end of the day all the workers in the hall are covered with a goldencoloured layer of tea fluff.

Mechanical blending is much faster than the manual process, the daily output being as high as $50000 \mathrm{~kg}$. The machine is fitted with dust extractors and therefore little fluff escapes. The tea to be blended is emptied into a hopper from which a conveyor belt carries it through a dust extracting chamber to the bottom of a vertical shaft. A system of revolving buckets takes the tea up the shaft into a large tank fitted with a mixing fan. The partially blended product is then led for further mixing into four smaller tanks in which the fans rotate in the opposite direction. The tea is then packed in boxes for export.

The fluff extracted from the conveyor belt as well as from the tanks is carried along a system of wide ducts to a far corner of the hall where most of it is collected into bags. The remainder is directed into a cubicle fitted with jets of water which precipitate the fluff. This dual system of dust disposal provides a safeguard against the clogging of the mechanism with tea fluff.

\section{Methods}

One hundred and twenty-five workers in the tea blending factory who were directly engaged in blending and regularly exposed to tea fluff were examined clinically and radiographically at the Central Chest Clinic, Colombo. Categories of workers such as office staff, watchers, mechanics, and lorry drivers were excluded from the study. The first round of examinations was conducted in March 1976, and subsequent examinations were carried out in November 1976 and October 1978. Coverage of the entire work force was achieved by having these successive examinations. Twentyeight workers who missed the first two rounds were included in the final examination. By 1978, five workers had retired on reaching the age limit of 55 years. The age and period of service are taken as those prevailing at the time of the last examination in the respective workers.

An occupational history was obtained from each worker who was also questioned according to a questionnaire based on that of the Medical Research Council questionnaire on respiratory symptoms, modified to suit the local conditions. A clinical examination with emphasis on the respiratory system was carried out. A chest radiograph was taken. Sputum examination by direct smear and culture for tubercle bacilli, white blood cell and differential counts, and erythrocyte sedimentation rate determination were also done if necessary.

\section{Results}

Most of the workers were men (table 1). Their average age was $44 \cdot 1$ years and their average period of service in the tea blending industry 22.9 years. One hundred and four $(83.2 \%)$ of the 125 workers had served for over 20 years (table 2). None of the workers had been employed in any other industry before joining the present one.

Table 1 Age and sex distribution of tea workers studied

\begin{tabular}{lccc}
\hline $\begin{array}{c}\text { Age group } \\
(y r)\end{array}$ & Men & Women & Total \\
\hline $20-29$ & 9 & 0 & 9 \\
$30-39$ & 15 & 2 & 17 \\
$40-49$ & 57 & 14 & 71 \\
$50-55$ & 27 & 1 & 28 \\
Total & 108 & 17 & 125 \\
\hline
\end{tabular}

Table 2 Number of workers with respiratory disease with length of service

\begin{tabular}{lrllcr}
\hline $\begin{array}{l}\text { Length of } \\
\text { service } \\
\text { (yr) }\end{array}$ & $\begin{array}{l}\text { Chronic } \\
\text { bronchitis }\end{array}$ & Asthma & $\begin{array}{l}\text { Pulmonary } \\
\text { tubercu- } \\
\text { losis }\end{array}$ & $\begin{array}{l}\text { Free of } \\
\text { respiratory } \\
\text { disease }\end{array}$ & Total \\
\hline $1-5$ & 1 & 0 & 0 & 7 & 8 \\
$6-10$ & 1 & 0 & 0 & 3 & 4 \\
$11-20$ & 1 & 1 & 0 & 7 & 9 \\
$21-30$ & 28 & 7 & 6 & 59 & 100 \\
$31-40$ & 0 & 0 & 1 & 3 & 4 \\
Total & 31 & 8 & 7 & 79 & 125 \\
\hline
\end{tabular}

Chronic bronchitis was considered to be present when there was a history of cough and phlegm during most days for at least three months of at least one year. The condition was diagnosed in $31(24 \cdot 8 \%)$ workers of whom five were women. Wheezes were heard over the chest at one time or another in 15 workers. The average age of the affected workers was 44.8 years, and their average period of service 24.8 years. Twenty-eight of the 31 workers with chronic bronchitis had worked for over 20 years in the industry. The workers with chronic bronchitis smoked an average of 5.7 
cigarettes a day (SD 6.1), while the figure for the study population as a whole was 4.7 cigarettes a day (SD4.9). There were nine non-smokers among the workers with chronic bronchitis while there were 29 in the entire study population. All the women were non-smokers, and this finding is not unexpected as women in Sri Lanka rarely smoke. Eight $(6.4 \%)$ workers had asthma which was defined as a disease characterised by narrowing of the intrathoracic arways indicated by dyspnoea or wheezing varying in severity over short periods of time. ${ }^{4}$ Reversibility tests were not done. Seven of these subjects had developed the condition after starting to work in the industry and their average length of service at the time of onset of asthma was 11.7 years. At least three of the affected workers gave some indication that their asthma had some connection with their occupation. One of them could not continue in the blending section because of frequent attacks of asthma and he was given employment in the canteen. Another said that his condition was aggravated by the dust, while the third stated that his asthma was less on the days when he stayed off work.

Evidence of active or inactive pulmonary tuberculosis was found in seven $(5.6 \%)$ of the workers. Three of them were active cases with positive sputum detected for the first time, while three others had been treated previously and were now inactive. These six cases had contracted the disease while being employed as tea blenders, their average length of service up to the time of diagnosis being 21.2 years. The remaining worker showed evidence of healed tuberculosis though untreated in the past.

When the workers were re-examined two years later there was no significant change in their clinical and radiographical status except in the three active cases of tuberculosis who had improved with treatment.

\section{Discussion}

The numerous tea factories in Sri Lanka engage a considerable labour force in the manufacture of tea, but only a few in each factory are directly exposed to the fluff. The largest concentration of workers exposed to this dust is found in the few tea blending institutions in Colombo. Most of these firms employ casual labour with short periods of service, but the one selected for the present study had a regular labour force with an average of 22.9 years of service, and this was an obvious advantage in assessing the effect of tea dust on the workers. Further, the fact that their occupational history was uncomplicated by previous exposure to other dusts makes them most likely to exhibif any adverse effects of exposure to tea dust.

A total of $46(36 \%)$ out of 125 workers haबे chronic respiratory disease. This is a very high prevalence when compared to the presence of respiratory symptoms in only $4.7 \%$ of the genera population. ${ }^{5} \mathrm{~A}$ suggestion has been made $\overrightarrow{b \vec{y}}$ Fernando ${ }^{6}$ that the incidence of respiratory illnes could be reduced by the provision of well-designed exhaust equipment in sifting and blending room The results of the present survey support such s. ST call for preventive measures.

Chronic bronchitis is an uncommon conditio $\vec{\theta}$ in Sri Lanka. According to official figures for 1974 there were only 493 hospital admissions per 100000 population for the whole country. The low consumption of tobacco by smoking and the relatively low atmospheric pollution are the prots able factors responsible for this low prevalence Therefore the occurrence of such an uncommod condition in nearly a quarter of the workers epidemiological evidence in support of an aetion logical relationship with tea dust.

It is relevant to enquire into the prevalence of chronic bronchitis in other local industries wi comparable working conditions. In a survey 793 coir workers exposed to a dust which is con sidered inert, only three $(0.3 \%)$ cases of chron bronchitis were detected. ${ }^{7}$ The coir and tea workers came from the same social class and lived undef similar environmental conditions in the suburbs of Colombo. On the other hand, tea blenders mas by placed in the same category as kapok ginne in whom chronic bronchitis was diagnosed 鲐 $17 \cdot 1 \%{ }^{8}$

Twenty-eight out of the 31 workers with chrongc bronchitis had worked for over 20 years in the industry. This suggests that chronic bronchitis is related to long-term exposure to tea dust.

Asthma of occupational origin is a wet recognised entity and its occurrence as a result $\overline{\mathrm{f}}$ exposure to tea fluff has been previously reported? The finding that eight workers suffered from the condition is in line with such previous experienow This prevalence is much higher than in the popy lation, an indication of which is demonstrated the finding of only six $(0.8 \%)$ cases of asthma 779 coir workers. ${ }^{7}$ This difference is statistical significant $\left(\chi^{2}=22 \cdot 4\right)$.

The incidence of pulmonary tuberculosis in Lanka is one of the lowest in South-East Asia, the figure for 1977 being 37.6 new cases per 1000 g0 population. With regard to the prevalence of actiye and inactive pulmonary tuberculosis in the con- 
munity, there were 905 people with suspected or definite radiographical evidence of tuberculosis among 27095 persons examined. ${ }^{5}$ In the present study there were seven such cases among 125 workers. This difference is not statistically significant $\left(\chi^{2}=1.96\right)$, and therefore it is unlikely that pulmonary tuberculosis is aetiologically related to exposure to tea dust.

\section{References}

1 Castellani A, Chalmers AJ. Manual of Tropical Medicine, 3rd ed. London: Baillière, Tindall and Cox, 1919: 1890.

2 Uragoda CG. Tea maker's asthma, $\mathrm{Br} \mathrm{J}$ Ind Med 1970; 27:181-2.
3 Ebihara I. Inhalative allergy of the ciliae of tea leaves. J Sci Lab 1975; 51:661-6.

4 British Thoracic and Tuberculosis Association. Skin tests and clinical features of asthma. $B r J$ Dis Chest 1975; 69:125-36.

5 National Tuberculosis Survey Team and WHO Regional Tuberculosis Training and Evaluation Team. Report on Tuberculosis Baseline Survey, Ceylon, 1970-71. Colombo (mimeographed), 1971.

6 Fernando LVR. In: Encyclopaedia of Occupational Health and Safety. Geneva: International Labour Office 1971; 2:1389.

7 Uragoda CG. A clinical and radiographic study of coir workers. Br J Ind Med 1975; 32:66-71.

8 Uragoda CG. An investigation into the health of kapok workers. Br J Ind Med 1977; 34:181-5. 